\title{
Users and health professionals perceptions of medication labels: a qualitative
}

\section{approach}

\author{
Percepções sobre rotulagem de medicamentos por usuários e profissionais de saúdle: uma \\ abordagem qualitativa \\ Percepciones sobre el etiquetado de medicamentos por parte de usuarios y profesionales de la
}

salud: un enfoque cualitativo

Received: 01/18/2021 | Reviewed: 01/21/2021 | Accept: 01/22/2021 | Published: 02/03/2021

Priscila Farfan Barroso

ORCID: https://orcid.org/0000-0002-4815-4792

Hospital Moinhos de Ventos, Brazil

E-mail: prifarfan@gmail.com

Cassia Garcia Moraes

ORCID: http://orcid.org/0000-0002-5270-1883

Hospital Moinhos de Ventos, Brazil

E-mail: cassia.pagano@hmv.org.br

Maicon Falavigna

ORCID: http://orcid.org/0000-0002-2637-6837

Hospital Moinhos de Ventos, Brazil

E-mail: maicon.falavigna@hmv.org.br

Lisana Reginini Sirtori

ORCID: https://orcid.org/0000-0002-6352-9572

Agência Nacional de Vigilância Sanitária, Brazil

E-mail: lisana.sirtori@anvisa.gov.br

Fernanda Horne da Cruz

ORCID: https://orcid.org/0000-0001-5772-2803

Agência Nacional de Vigilância Sanitária, Brazil E-mail: fernanda.cruz@ anvisa.gov.br

Emilia da Silva Pons

ORCID: http://orcid.org/0000-0003-4881-8728

Hospital Moinhos de Ventos, Brazil

E-mail: emiliapons@yahoo.com.br

\begin{abstract}
This study analyzed the labeling of medications in Brazil based on the perception of health professionals and users in order to propose modifications and improvements that avoided the error of medication use. The qualitative approach was used to collect data, and the semi-structured interview technique was performed among health professionals and the focal group technique among the users. This collection took place throughout 2017. The main difficulties encountered by drug product respondents were similar labels, the difficulty of finding the items on the labels, the different information on the primary and secondary packaging of the medicines and the difficulty in visualizing information in the labels. And the suggestions were to remove the unnecessary information labels that are considered obvious; and adding or highlighting the dosage information area, the route of administration, the mode of preparation of the medicines and storage form for preservation. About the general modifications there was agreement on the definition of color of the label according to the pharmacological action of the drug and on the standardization in the increase of letter of the main information of the label.
\end{abstract}

Keywords: Labeling of medicines; Shape perception; Use of medicines.

\section{Resumo}

Este estudo analisou a rotulagem de medicamentos no Brasil a partir da percepção por parte de profissionais de saúde e de usuários de medicamentos a fim de propor modificações e melhorias que evitem erros no uso de medicamentos. A abordagem qualitativa foi utilizada para a coleta de dados, que ocorreu ao longo de 2017. Utilizou-se a técnica da entrevista semiestruturada entre 30 profissionais de saúde e a técnica de grupo focal entre 8 grupos de usuários. As principais dificuldades dos entrevistados com os rótulos de medicamentos foram a semelhança entre os rótulos, a dificuldade de encontrar informações nos rótulos, a diferença de informações presentes nas embalagens primárias e secundárias dos medicamentos e a dificuldade na visualização de informações nos rótulos. As sugestões foram retirar dos rótulos informações desnecessárias e que sejam consideradas óbvias; e acrescentar ou destacar a área de informações posológicas, a via de administração, o modo de preparo dos medicamentos e forma de armazenamento. 
Houve consenso na definição de cor do rótulo conforme a ação farmacológica do medicamento e na padronização do aumento de letra das principais informações do rótulo.

Palavras-chave: Rotulagem de medicamentos; Percepção de forma; Uso de medicamentos.

\section{Resumen}

Este estudio analizó el etiquetado de medicamentos en Brasil a partir de la percepción por parte de profesionales de salud y de usuarios de medicamentos a fin de proponer modificaciones y mejoras que eviten errores en el uso de medicamentos. El abordaje cualitativo fue utilizado para la recolección de datos, que ocurrió a lo largo de 2017. Se utilizó la técnica de la entrevista semiestructurada entre 30 profesionales de salud y la técnica de grupo focal entre 8 grupos de usuarios. Las principales dificultades de los entrevistados con las etiquetas de medicamentos fueron la similitud entre las etiquetas, la dificultad de encontrar información en las etiquetas, la diferencia de información en los envases primarios y secundarios de los medicamentos y la dificultad en la visualización de información en las etiquetas. Las sugerencias fueron retirar de los rótulos información innecesaria y que se consideraron obvias; y añadir o destacar el área de información posológica, la vía de administración, el modo de preparación de los medicamentos y la forma de almacenamiento. Hubo consenso en la definición de color de la etiqueta conforme a la acción farmacológica del medicamento y en la estandarización del aumento de letra de las principales informaciones de la etiqueta.

Palabras clave: Etiquetado de medicamentos, Percepción de forma, Uso de medicamentos.

\section{Introduction}

A medication error is any preventable event that may cause or lead to inappropriate medication use or patient harm (Brasil, 2009). Globally, the cost associated with medication errors has been estimated at US\$ 42 billion annually or almost $1 \%$ of total global health expenditure (WHO, 2017). In the United States, medication errors account for almost $20 \%$ of all medical errors (Berman, 2004). In Brazil, despite the lack of accurate records, in part due to poor reporting, in 2015, the National Health Surveillance Reporting System (Notivisa) received 31,786 reports of 'health care-associated adverse events' across the country, of which 1,143 involved medications.

The causes of these errors are multifactorial and may be associated with professional practice, process failures, communication problems, and even with medication labeling problems (Cohen, 2006; Brasil, 2014; WHO, 2011). The most common causes associated with errors are brand or generic names that look alike or sound alike, look-alike packaging, and unclear, ambiguous or incomplete label information (Koh, Corriga \& Donalson, 2000; IMSN, 2013).

In addition to factors related to medication labeling, there are factors intrinsic to the users, such as cognitive characteristics, which may impair comprehension of written medicine information escritas (Sahm, Wolf, Curtis, Behan, Brennan, Gallwey \& Mc Carthy, 2012; Luk \& Aslani, 2011). Therefore, it is essential that packages and labels be designed to meet the users' needs, such as providing information important to the proper identification of the product, and with consideration of the environment in which the product will be used, stored, prescribed, and administered (Health Canada, 2015).

In the context of medication use, where safety is of paramount concern, evaluating users and health professionals perceptions may contribute to improving labels and, consequently, preventing potential medication errors. Although previous studies and reports have shown quantitatively the association between label comprehension and medication errors, there is little understanding of how this phenomenon occurs.

The objective of the present study was to examine users and health professionals perceptions of medication labels, especially regarding the occurrence of medication errors, in order to gain further understanding of this phenomenon and suggest improvements. 


\section{Methodology}

Two different qualitative research techniques were used to collect data on users and health professionals perceptions of medication labels in Brazil. Focus groups with medication users and semi-structured interviews with health professionals were conducted from April to June 2017.

A qualitative approach was used in this study. According to Minayo (2014), the qualitative method is appropriate for investigating perceptions because it allows researchers to explore the range of interpretations that subjects produce throughout their lives in order to make visible the issues related to the phenomenon of interest. In this respect, researchers study their subject matter attempting to interpret phenomena in terms of the meanings people bring to them (Denzin \& Lincoln, 2006).

Based on this approach, an exploratory field study was first conducted aiming to become familiar with the subject matter (Gil, 2002) on the premises of a hospital located in Porto Alegre, the capital of Rio Grande do Sul, the southernmost state of Brazil. After understanding the flow of medicines within the hospital and reviewing the questionnaires, two techniques were defined for data collection: semi-structured interviews with health professionals and focus groups with medication users.

\subsection{Semi-structured interviews}

We developed an interview guide with 12 open-ended questions (Box 1) related to professional experience, perceptions of medication labels, and suggestions for label improvements. Professional categories were defined as those involved in dispensing and administering medications and divided into hospital pharmacists (HP), health care registered nurses $(\mathrm{RN})$, health care practical nurses (PN), health care pharmacy technicians/assistants (PA), retail pharmacists (RP), and pharmacy clerks $(\mathrm{C})$.

Data were collected from a convenience sample of 30 health professionals, with one respondent from each professional category from each of the five Brazilian macro-regions (North-N, Northeast-NE, South-S, Southeast-SE and Midwest-CO). The interviewees were appointed by the risk managers of the Network of Sentinel Hospitals of the Brazilian National Health Surveillance Agency (ANVISA). All interviews were conducted by telephone and recorded for subsequent analysis and quality control.

The informed consent form was read aloud to each participant prior to the interview. All telephone interviews were conducted by an anthropologist in a private room using the 12-question semi-structured interview guide. The CallReplay system was used to record the interviews. Each interview lasted from 15 to 30 minutes. At the end of the process, all interviews were transcribed in full and the content was analyzed using NVivo software.

\subsection{Focus groups}

The focus group technique, according to Minayo (2004), allows researchers to more accurately capture the issues related to the phenomenon of interest, to extract information that is peculiar to a particular group of subjects, and even to develop hypotheses for the research. Therefore, based on the responses provided, it is possible to examine not only the description but also the explanations and level of comprehension of the phenomenon of interest. The technique was used in this study to allow a more in-depth exploration of medication users perceptions.

Participants were recruited at places with a high flow of people in Porto Alegre and through snowball sampling with the use of a structured filter consisting of questions related to the profile of the respondents. Thus, groups were defined based on determinants of sex (men $[\mathrm{M}]$ and women $[\mathrm{W}]$ ), education $(<8$ years of schooling $[-8 \mathrm{y}]$ and $\geq 8$ years of schooling $[+8 \mathrm{y}])$, and age (adults aged 18 to 54 years [Y] and 55 years or older [O]). Individuals who had used any medication in the 12 months prior to selection were eligible for inclusion. Written informed consent was obtained from all participants. 
Eight focus groups were arranged based on the sociodemographic profile of the participants, for a total of 62 individuals. Each group consisted of 6 to 8 individuals, although 10 to 12 people had been recruited per group. All focus group sessions took place in a room with a one-way mirror and were conducted by a moderator, with the support of two assistants, using a discussion guide with questions about medication use (Box 2). All sessions were transcribed in full and analyzed descriptively and analytically, with the support of notes taken during the sessions, using NVivo, Excel, and Sphinx.

\subsection{Data analysis}

After collection, the data were selected, coded and tabulated as proposed by Marconi and Lakatos (2003). Data selection was based on the analytical categories established by the questions made during the interviews and focus group sessions, searching for a recurrence pattern of the above-mentioned aspects. The responses were then presented as empirical categories brought up by the respondents through their perceptions of medication labels. At the end, possible changes and improvements in medication labels were proposed in order to contribute to reducing medication errors in Brazil. These empirical categories are in italics throughout the text.

\section{Results}

A total of 30 health professionals were interviewed, covering all five Brazilian macro-regions; there were 22 women and 8 men, with age ranging from 25 to 41 years. Seven focus groups had 8 participants, while only one focus group had 6 participants.

For the presentation of the results, analytical categories were derived from the issues raised by health professionals and from the discussions in the focus groups, as follows:

(i) visual appearance of labels;

(ii) identification of information;

(iii) comprehension of information;

(iv) changes in labels.

\subsection{Visual appearance of labels}

Regarding the visual appearance of labels, health professionals report that look-alike labeling accounts for one of the main difficulties in handling medicines. They point out as features that look alike the design of labels, similar colors, the description of names, and information printed on the labels. The situation is further aggravated when dealing with different products from the same manufacturer, as their labels differ only in specific information.

Oh from manufacturer $\mathrm{x}$, fenoterol and ipratropium bromide, the two are the same color, same size, $20 \mathrm{~mL}$ the two of them, they're the same thing. We have to pay close attention to what is written on them. Ipratropium and fenoterol. If we don't, we end up mistaking one for the other. $(\mathrm{C}, \mathrm{SE})$

Another issue addressed by health professionals is the lack of differentiation between biosimilar and reference products. They point out that, without a color stripe for identification, as the yellow stripe used to indicate generic drugs, biosimilar medicines can be confusing, as suggested below: 
I think my difficulty is the following: biosimilars look too much alike the brand-name drugs, so we get a little like, "is it a biosimilar or a brand version?". There is no clear-cut difference, as with generics. The color stripe helps us identify it right away, [but] with biosimilars, I'm always in doubt. I have to do some research to be sure if it is or isn't [the same as the brand-name drug]. (RP, CO)

The respondents also highlight the appearance of small-volume parenteral solutions (infusion containers, ampoules, vials, closed systems) as a risk factor for the occurrence of adverse events while dispensing and administering medications, mainly due to medication mix-ups. A nurse explains the difficulty in differentiating between containers with similar design and layout:

The glucose $50 \%$ container is equal to that of the $25 \%$, that is, there is nothing to differentiate between their concentrations. Of course, potassium comes in a different form [than] the glucose.... But it happens quite often in the hospital I work during my visits. I see that drum full of these plastic containers, then I say, "People, why is chloride together with potassium?". I always have to call their attention. (RN, N)

Different from health professionals, who handle and administer several medications per day, most medication users in the focus groups report no problems related to look-alike labeling. Users are already familiar with their most commonly used medications, as shown in the excerpt below:

I'm used to the package colors of my medicines, they've been the same for years. So, for me, what matters is how I organize them [at home], because I already know their colors. (W, Y, $-8 \mathrm{y}$ )

\subsection{Identification of information}

As for the identification of information presented on the label, participants find it difficult to locate on the label important information required to correctly use the medication. Medication users, regardless of sex, age or level of education, report difficulty in locating information on the labels. One respondent states that, "The first time we buy it [the medicine], we are like 'Oh, there it is [information on medication use]!'. But we [have to] look for it a little bit.” (W, Y, +8y)

Another issue addressed by medication users is different information in primary and secondary packages, since not all information provided on the secondary package is also available on the blister packs, making it difficult to recover such information later. The situation is further aggravated by the common practice of discarding the outer package, as reported by users, keeping only the primary package in their 'medicine box'. As mentioned by one of the users, important information may be lost:

And, sometimes, the batch number is not printed on the blister pack. When it is, it's so difficult to see it, because the blister pack is often made of foil, and this material makes it difficult... [...] And there are also the components and the batch that are only printed on the box. On the blister pack, sometimes, I find it difficult even to identify the name... $(\mathrm{M}, \mathrm{O},-8 \mathrm{y})$

Health professionals, in turn, report that it is a common practice in health care facilities to manually fractionate the components of blister packs. Therefore, information printed across the entire blister strip is divided or lost. In addition to losing product information and wasting time in the process, this practice may lead to misinterpretation of information on the resulting blister pockets. In this respect, respondents point out that information on dose should be printed on each blister pocket by the manufacturer, thereby gaining time for health professionals and preventing errors in the process, as reported in the following statement: "And then there are the blister packs inside, that are also... it would be better for patients if they were individualized." (PN, SE).

Also, both health professionals and medication users refer to a difficulty in viewing information on the labels, 
especially expiration date and batch number. An older man, with more than 8 years of schooling, says that, "Expiration date is always hidden, isn't it?". They have also reported that, when information and numbers are found, they are provided in small font size. And when the text is embossed or debossed onto a package, the visibility of information is reduced, and the numbers look alike, as reported by a health professional:

Because there are no Ministry of Health standards, they handle it as they wish. Some manufacturers put it in a different way, not as a print, I don't know, as if they use a press machine or something like that, and [then] it's too difficult to see that expiration date. (RP, NE)

It should be noted that Brazilian legislation, through ANVISA regulations, establishes that imprinting (embossing or debossing) should not be the only method of displaying expiration date on a package. However, not all manufacturers comply with these regulations, resulting in disparities on how this information is displayed. Medication users, including young adults with more than 8 years of schooling, also find it more difficult to locate and read this information when the text is embossed or debossed on the package. A male user says that, "We can't read what's imprinted there. It's impossible to read it!".

Regarding how information is provided on the packages, respondents point out that some alterations may occur over time. When the label is affixed to the package, for example, it may be detached or erased with time, thus important information on medication use may be lost. Some medicines are marketed with illegible labels, thus impairing the readability of information, as reported in the following statement: "I think the most difficult thing is to identify batch number and expiration date, because, sometimes, they are in such a small size or in a way as they've been erased." (RN, S)

Health professionals have mentioned that there is a risk of confusion when only the date of manufacture, rather than the expiration date, is displayed on the label (e.g., when the label reads 'shelf life: 2 years'). These difficulties are enhanced for ampoules. They report that, because of the small size of the ampoules, information is displayed in an even smaller font size and in font color without contrasting background, impairing readability, as reported below:

[The difficulty] is on ampoule labels, because they're smaller. The label is very small, tiny little letters, and, sometimes, packages look too much alike. So, when we deal with products from the same manufacturer, we end up receiving identical vials, even in the same color sometimes, only the drug name is different. So, this is what I see as a difficulty. (PN, SE)

In addition, ampoules are commonly made of glass and information is written with a font color that hinders readability; therefore, health professionals often have to ask other professionals for help on how to use that medication or even to place a finger behind the vial to help information 'stand out' so that it can be read. Type style, such as cursive and script fonts, may also hinder the comprehensibility of medication labels, especially if used for the name of the medication, generating doubts about the product.

As for the display of medication label information, as mentioned throughout the text, a major difficulty is small font size. Health professionals report difficulty in reading some labels, mainly information related to the name of the active ingredient, drug concentration, amount of the product, date of manufacture, and expiration date. The situation is further aggravated when the health professional has a vision problem and wears glasses or is working the night shift.

Some labels have very small letters, making it difficult to read them during the night shift, when the workflow is different. There are some tiny little letters that we can barely identify them, especially if used for medications, ampoule labels. So, in some medicines, the name is so small that we can barely see it. (RN, NE)

Different user profiles also reinforce the existence of this difficulty. A young man, with more than 8 years of 
schooling, has reported that the brand name is printed in increased font size compared with the name of the active ingredient. A young woman, with more than 8 years of schooling, states that, "Sometimes, letters are so tiny that it is, really, a little [difficult to understand]. And, sometimes, [a letter] is hidden in a corner and, if we don't know the medicine...".

\subsection{Comprehension of information}

Medication users, both men and women, regardless of age and level of education, report major difficulty in understanding scientific jargon on the labels. An older man, with more than 8 years of schooling, has reported that the content of labels "sounds like a coded language that is inaccessible to the vast majority." This issue is underscored by another respondent, as follows: “They could use simple language. Because they use medical jargon, ‘whatever-floxacin' and so on. I'm a layman, I don't know it.” (M, Y, -8y) In this respect, users search the Internet in an attempt to find useful information to help them understand what they refer to as a 'mystery', as reported in the following statement: "We don't know many of the words, we have to consult Dr. Google to solve the mystery.” (M, Y, +8y) Some users have also reported that they seek help mainly from their family members to understand medication labels.

\subsection{Changes in labels}

The suggestions of medication users and health professionals for label improvements involve strategies to overcome current deficiencies and change labels. When asked about the need to remove information from the labels, most health professionals report that there is no need to remove current information, as they consider it basic, essential, and useful information. However, some suggestions refer to information that can be confusing or that might be provided only in the package inserts.

Medication users feel that obvious information is unnecessary, such as 'prescription only medicine', since the red or black stripe already indicates such a need, or even warnings on medication misuse and to consult a doctor if necessary. Other pieces of information deemed unnecessary are 'immediate relief' and 'sleep better at night', among others. Such information is viewed as product advertising and not relevant to medication use.

As for adding information to medication labels, some health professionals and medication users understand that it is important to add an area for dosage information. That is, leaving space on the labels for the physician or even the patient to write information on time, dates, dosage, and instructions on medication use, aiming to promote the correct use of the medication. Also, for long-term use medicines, they suggest adding the days of the week to the blister pack to help users check whether or not they have taken the medication, as explained by a respondent:

I think it's something important on the blister pack... as the hormone I take every day, it's there... I buy the original one, and the days of the week are printed on the blister pack, Monday, Tuesday, Wednesday, Thursday... The generic one, no, nothing is written on the pack. So, we, older people, we [think]: "Did I take it, did I not take it?" (W, O, +8y)

Health professionals consider important to display information on route of administration on the labels and emphasize that it is necessary to highlight on the labels whether the medication should be administered by the intramuscular, subcutaneous or intravenous route, as well as to indicate the mode of preparation of medications. Respondents working in hospitals report that, if this information was available on the label, the number of instruction sheets on mode of preparation (such as dilution and type of diluent) that are spread out in health care facilities would be reduced.

A consensual suggestion, agreed upon by health professionals and medication users, is defining the color of the label according to the pharmacological action of the medication, since the possibility of identifying medications by color-coded labels, containers, and ampoules would lead to a more effective differentiation between products. One user points out that the 
use of similar colors for different medicines can be confusing: "Then, it's time for that [medicine] from the blue box. Which blue box? There are three of them! The slim one. But the three are slim. And then, which one should I take?” (W, Y, +8y)

One respondent explains that colors help differentiate between medicines that are taken every day:

I take care of my grandma, she's 94. She takes this medicine, Buscopan, a lot, so I go buy it for her. There are three types, three colors of boxes. Then, hers, is always the little blue one. I ask her: is it the little blue or little purple one? Then, when I get to the drugstore, its Buscopan Compositum, the little blue box. (M, O, +8y)

As an example of the suggestion for identification of medications, another user says, "It should be like kisuco (juice powder), the same package but in different colors. [...] by drug class. The same layout, just like kisuco.” (M, O, +8y)

Health professionals also suggest the use of color to highlight the concentration of medications, especially of high-risk medications. In the same vein, the following suggestions are also made: using color stripes to highlight different information of the same medication (e.g., different concentrations); applying different features, such as colors and shapes, also to glass containers and vials of look-alike medications, facilitating handling.

Although many respondents have proposed the use of colors for rapid differentiation of medication actions, some of them feel that the wide variation of colors may lead to 'visual pollution' and even impair the comprehension of information required to correctly use the medication. Others have even mentioned that very colorful labels may arouse the desire of children to use them: "I also see it as dangerous for children. It's very colorful. [...] It calls their attention." (M, Y, -8y) Colorful packages may call the attention of children, making them think that they contain sweets or candies. Therefore, caution is needed when arranging colors on the labels.

There is also consensus among study participants about standardization in increasing the font size for key information on medication labels. Increased font size should be used to emphasize information on brand name, name of the active ingredient, concentration, route of administration, storage conditions, expiration date, and batch number. Health professionals point out that such practice would make information more legible and clearer, regardless of the age of whom is reading the label, of the light conditions of where the label is being read, and of the color of the information being sought. Users suggest that expiration date should be written in larger font size and on a standardized location for easy identification.

Other general changes suggested for labels reached no consensus between medication users and health professionals. One of these discrepant opinions is describing the indications for use and contraindications on the label. For health professionals, such information should appear only in the package inserts, because they take up much space from the labels and may lead to incorrect use of medications or promote self-medication. Medication users, however, find it important that labels indicate 'for what' the medication should be used in order to help them recognize the relationship between product and illness.

They also consider it important to have access to information aimed to people with allergies, hypertension, diabetes, and possible drug interactions. Thus, users suggest the inclusion of a 'basic summary' of the package insert on the package, with indications for use, contraindications, dosage, side effects, methods of product preservation, as explained by a medication user: "I think the package insert could be on the back of the box. [...] A summary, of course." (M, Y, -8y) Anyhow, it should be noted that, among users, men preferred 'clearer and more objective' labels, while women preferred labels with 'more complete information'.

Another disagreement refers to information on product manufacturing, such as the pharmacist in charge of manufacturing and address of the manufacturer. Users feel that such information should be provided only in the package insert, viewing this as a waste of space on the labels. In one of the focus groups, a participant states, "It's not the type of information we read at first." (W, Y, $-8 \mathrm{y}$ ) Some health professionals, however, understand that such information can be relevant to their work and would allow proper identification of medications. 
It remains controversial the issue about describing the brand name and the name of the active ingredient on the label. One user says, “...that, in certain packages, the components of the medicine [...] have ugly names that we don't understand.” $(\mathrm{W}, \mathrm{O},-8 \mathrm{y})$, indicating that this information may impair comprehension and, therefore, should not be displayed on the label. Some users suggest that the brand name should be displayed even on the package of generic medicines. Health professionals, in turn, believe that the two names on the label are important to identify both brand-name and generic medicines. Nevertheless, junior health professionals appear to become confused with the correspondence between medication names:

Because when we have a new pharmacist, he keeps asking me all the time: "Hey, Lú, what's the medicine?". Because it comes as metoclopramide, but... I'm giving Plasil as an example, because he asked me once about it. The person may be in doubt. So, a health care person who has just started may have these doubts as well. There are so many medicines, even I get in doubt sometimes, and I have some experience in nursing... about some new medicine, that is new in the market. (PN, SE)

Regarding the size of color stripes on the labels, although health professionals consider their presence useful to differentiate a generic medicine from other medicines, they feel that the size of the stripe takes up too much space from the package, leaving little space for other information. However, for medication users, larger print for identification of generic drugs, with an uppercase $\mathrm{G}$, and the red and black stripes help to draw more attention and differentiate these medicines from others.

\section{Discussion}

Both health professionals and medication users reported difficulties in handling and administering medications. The issues raised by them point to situations that may hinder or confuse the differentiation between medications, jeopardizing patient safety and leading to incorrect use of medications.

The participants brought to attention several difficulties and offered some reflections on medication labeling problems, which are associated with medication errors. It was clearly difficult for them to find the name of the medication because of its location, type style, font size and color, in addition to the lack of standardization among manufacturers.

Look-alike labeling stood out as a major problem by hindering an effective differentiation between medications, which may lead to medication mix-ups during dispensing and administration, especially among health professionals. Ampoules and vials accounted for some of the main complaints. As previously reported (Lopes, Neri, Madeira, Neto, Lélis, Souza, Oliveira, Costa, \& Fonteles, 2012), small-volume parenteral solutions (infusion containers, ampoules, vials, closed systems) posed the greatest risk for adverse events while administering medications, especially among health professionals.

Health professionals explained that other issues related to their work routine may contribute to medication errors due to labeling confusion, such as work overload, working hours, and double shift. They feel that these factors reduce their level of attention when selecting, preparing and administering medications, making it difficult to differentiate between look-alike labels. This explanation of a lack of attention among health professionals has also been mentioned in a previous study (Miasso, Grou, Cassiani, Silva, \& Fakih, 2006), attributing the causes of the errors to individual factors rather than to systemic factors.

The strategies mentioned by health professionals to avoid labeling confusion include being more careful when selecting medications, storing medications with look-alike labels at separate places, apart from each other, and using warning messages within the health care facility, such as messages on the prescription and dispensing computer-based system. In hospitals, medications are generally supplied by a few manufacturers, which often use similar labels across all their product lines, increasing the likelihood of medication administration errors, as also reported in a previous study in this field of 
research(Anacleto, Perini, Rosa \& César, 2005). A strategy employed by the respondents in the storage and dispensing process was to store look-alike and sound-alike medications apart from each other.

Many efforts have been undertaken in health care facilities to prevent medication errors. Given that medication labeling accounts for a significant proportion of these errors, changes aiming to improve the rate of correct identification of medication label information are very welcome. The study participants suggested some changes that may contribute to improving labels. For example, a recurring suggestion was that colors should be standardized across all medications from the same drug class and strong criticism was voiced against some manufacturers that standardize the layout and colors of packages and labels across all product lines manufactured by them. They believe that the use of similar colors on the packages make it difficult to read important information, which should be clear and objective, with symbols.

There was also a strong suggestion that doses should be individualized by the manufacturer, as already established by ANVISA Resolution No. 67 (Brasil, 2017). Medication users and health professionals agreed that information printed on blister packs may be lost, leading to errors or even loss of the medication, when such information is not repeated on each blister pocket by the manufacturer.

Users expressed a desire that clearer information on indications for use, contraindications, and restrictions on the use of the medication be displayed on the label, while health professionals did not agree that information on indications for use should appear on the label. A study (Cardarelli, Mann, Fulga, Balyakina, Espinoza \& Lurie, 2011) tested the use of colors on packages associated with the indications for which the medication was prescribed and found an improvement in medication adherence by users, especially among older adults, who are more likely to be on multiple medications at home and more vulnerable to adverse drug events.

The participants reported difficulty in viewing, identifying and distinguishing the name (brand name and/or active ingredient), dose, and expiration date, especially on blister packs. Therefore, suggestions for changes in color and font size for key information on medication labels appear to be relevant to improving the comprehension of information required to correctly use the medication.

Some discrepant opinions observed between health professionals and medication users also seem relevant, as they point to the different facets of medication use by demonstrating the differences between the health care setting and the home setting, where medications are used by laypeople. According to Fainzang (2001), the study of the social order in the life of individuals allows us to access what they perceive as the healing process and the meanings attributed to it in the home setting. With this understanding, it is possible to propose changes in medication labels that also make sense for laypeople.

\section{Conclusion}

The analysis of the empirical categories brought up through health professionals and medication users perceptions of their relationships with medication labeling allows improvements in labels aiming to increase patient safety and prevent medication errors. The main difficulties reported by the respondents in relation to medication packages were look-alike labeling, difficulty in locating items on the labels, different information in primary and secondary packages, and difficulty in viewing information on the labels. It was therefore suggested that obvious information, deemed unnecessary, should be removed from the labels, that an area for dosage information should be added to the labels, and that emphasis should be placed on the route of administration, mode of preparation of medications, and storage conditions for product preservation.

As for general changes, consensus has been reached on the following: defining the color of the label according to the pharmacological action of the medication and standardization in increasing the font size for key information on medication labels. However, no consensus has been reached on the following issues: displaying the indications for use and 
contraindications on the label (while users found it relevant, health professionals felt that it would lead to 'visual pollution' and promote self-medication); displaying information on product manufacturing (while users found it irrelevant, health professionals felt that such information would allow proper identification of medications); displaying the brand name and the name of the active ingredient (while users found that the brand name should be on the package of generic medicines, but there was no need for the name of the active ingredient to be displayed on the label, health professionals considered the presence of the two names essential on the label); and the size of color stripes on the labels, including the yellow stripe to indicate generic drugs and the red and black stripes (while users liked the combination of larger print and highlighting, health professionals felt that the stripes could be smaller in size).

Vulnerable points in medication labeling were perceived by health professionals and medication users. Medication use is increasingly becoming part of people's lives. Medications are used to relieve pain, treat chronic health problems, and prevent diseases. Therefore, measures that may contribute to improving labels not only can but also must be implemented in order to increase patient safety and prevent medication errors.

Thus, it is suggested that new labels for medicines include aspects pointed out in this research in order to facilitate the understanding of health professionals and users.

\section{References}

Anacleto, T. A., Perini, E., Rosa M. B., \& César, C. C. (2005). Medication errors and drug-dispensing systems in the hospital pharmacy. Clinics, 60(4): 32532 .

Anvisa. Ministério da Saúde. Resolução $n^{o}$ 4, de 10 de fevereiro de 2009. Dispõe sobre as normas de farmacovigilância para os detentores de registro de medicamentos de uso humano.

Anvisa. Ministério da Saúde. Resolução $n^{\circ}$ 67, de outubro de 2007. Dispõe sobre Boas Práticas de Manipulação de Preparações Magistrais e Oficinais para Uso Humano em farmácias.

Berman, A. (2004). Reducing Medication Errors Through Naming, Labeling, and Packaging. Journal of Medical Systems, $28(1)$ : 9-29.

Cardarelli, R., Mann, C., Fulga, K. G., Balyakina, E., Espinoza, A., \& Lurie, S. (2011) Improving accuracy of medication identification in an older population using a medication bottle color symbol label system. BMC Family Practice, 12 (1):142.

Cohen, M. R. (Org.). (2006). Medication Errors. (2nd Ed). Washington: American Pharmaceutical Association.

Denzin, N., \& Lincoln, Y. (2006). O Planejamento da pesquisa qualitativa: teorias e abordagens: ArtMed.

Fainzang, S. (2001). Médicaments et société. Le patient, le médecin et l'ordonnance. Collection Ethnologie Controverses: Presses Universitaires de France.

Gil, A.C. (2002). Como elaborar projetos de pesquisa. (4th ed): Atlas.

Health Canada. (2015). Good Label and Package Practices Guide for Prescription Drugs (Canadá); ISMP CANADÁ.

International Medication Safety Network. (2013) Position Statement - Making Medicines Naming, Labeling and Packaging Safer.

Koh, L. T., Corriga, J., \& Donalson, M. S. (Orgs.). (2000). To err is human: building a safer health system. Washington: National Academies Press.

Lopes, D. M. A., Neri, E. D. R., Madeira, L. S., Neto, P. J. S., Lélis, A. R. A., Souza, T. R., Oliveira, A. B., Costa, L. O. \& Fonteles, M. M. F. (2012). Análise da rotulagem de medicamentos semelhantes: potenciais erros de medicação. Revista da Associação Médica Brasileira, 58(1), 95-103. https://dx.doi.org/10.1590/S0104-42302012000100021.

Luk, A., \& Aslani, P. (2011) Tools used to evaluate written medicine and health information: document and user perspectives. Health Education \& Behavior. The Official Publication of the Society for Public Health Education, 38(4), 389-403.

Marconi, M. A., \& Lakatos, E. M. (2003) Fundamentos de Metodologia Científica. (5th. Ed): Atlas.

Miasso, A. I., Grou, C. R., Cassiani, S. H. B., Silva, A. E. B. C., \& Fakih, F. T. (2006). Erros de medicação: tipos, fatores causais e providências tomadas em quatro hospitais brasileiros. Revista da Escola de Enfermagem da USP, 40(4), 524-532. https://doi.org/10.1590/S0080-62342006000400011.

Minayo, M. C. S. (2004). O desafio do conhecimento: pesquisa qualitativa em saúde. (8th ed): Hucitec.

Ministério da Saúde. Documento de referência para o Programa Nacional de Segurança do Paciente. (1 ed). Ministério da Saúde.

Sahm, L. J., Wolf, M. S., Curtis, L. M., Behan, R., Brennan, M., Gallwey, H., \& Mc Carthy, S. (2012). What's in a label? An exploratory study of patientcentered drug instructions. European Journal of Clinical Pharmacology, 68(5), 777-782. 
Research, Society and Development, v. 10, n. 2, e3110212088, 2021

(CC BY 4.0) | ISSN 2525-3409 | DOI: http://dx.doi.org/10.33448/rsd-v10i2.12088

World Health Organization. (2011). Estrutura Concetual da Classificação Internacional sobre Segurança do Doente: World Health Organization.

World Health Organization. (2017) Medication Without Harm - Global Patient Safety Challenge on Medication Safety: World Health Organization. 